\title{
Genetic Dissection of Growth and Eco-Physiological Traits Associated with Altitudinal Adaptation in Sakhalin Fir (Abies sachalinensis) Based on QTL Mapping
}

\author{
Susumu Goto ${ }^{1, *}$, Hideki Mori ${ }^{2}$, Kentaro Uchiyama ${ }^{2}$, Wataru Ishizuka ${ }^{3}$ (D) Haruhiko Taneda ${ }^{4}$, Masaru Kono $^{4}$, \\ Hiromi Kajiya-Kanegae ${ }^{5}$ (D) and Hiroyoshi Iwata ${ }^{6}$
}

1 The University of Tokyo Forests, Graduate School of Agricultural and Life Sciences, The University of Tokyo, Tokyo 113-8657, Japan

2 Department of Forest Molecular Genetics and Biotechnology, Forestry and Forest Products Research Institute, 1 Matsunosato, Tsukuba 305-8687, Ibaraki, Japan; morih@ffpri.affrc.go.jp (H.M.); kruchiyama@affrc.go.jp (K.U.)

3 Forestry Research Institute, Hokkaido Research Organization, Koushunai, Bibai 079-0166, Hokkaido, Japan; wataru.ishi@gmail.com

4 Department of Biological Sciences, Graduate School of Science, The University of Tokyo, 7-3-1 Hongo, Bunkyo-ku, Tokyo 113-0033, Japan; taneda@bs.s.u-tokyo.ac.jp (H.T.); konom07@bs.s.u-tokyo.ac.jp (M.K.)

5 Research Center for Agricultural Information Technology, NARO (RCAIT), 2-14-1 Nishi-Shimbashi, Minato-ku, Tokyo 105-0003, Japan; h.kanegae@affrc.go.jp

Citation: Goto, S.; Mori, H.; Uchiyama, K.; Ishizuka, W.; Taneda, H.; Kono, M.; Kajiya-Kanegae, H.; Iwata, H. Genetic Dissection of Growth and Eco-Physiological Traits Associated with Altitudinal Adaptation in Sakhalin Fir (Abies sachalinensis) Based on QTL Mapping. Genes 2021, 12, 1110. https://doi.org/10.3390/ genes12081110

Academic Editor: Yordan S. Yordanov

Received: 18 June 2021

Accepted: 19 July 2021

Published: 22 July 2021

Publisher's Note: MDPI stays neutral with regard to jurisdictional claims in published maps and institutional affiliations.

Copyright: (c) 2021 by the authors. Licensee MDPI, Basel, Switzerland. This article is an open access article distributed under the terms and conditions of the Creative Commons Attribution (CC BY) license (https:/ / creativecommons.org/licenses/by/ $4.0 /)$.
6 Laboratory of Biometry and Bioinformatics, Department of Agricultural and Environmental Biology, Graduate School of Agricultural and Life Sciences, The University of Tokyo, 1-1-1 Yayoi, Bunkyo-ku, Tokyo 113-8657, Japan; iwata@ut-biomet.org

* Correspondence: gotos@uf.a.u-tokyo.ac.jp; Tel.: +81-3-5841-5493

\begin{abstract}
Background: The genetic basis of local adaptation in conifers remains poorly understood because of limited research evidence and the lack of suitable genetic materials. Sakhalin fir (Abies sachalinensis) is an ideal organism for elucidating the genetic basis of local adaptation because its altitudinal adaptation has been demonstrated, and suitable materials for its linkage mapping are available. (2) Method: We constructed P336 and P236 linkage maps based on 486 and 516 single nucleotide polymorphisms, respectively, that were derived from double digest restriction site-associated DNA sequences. We measured the growth and eco-physiological traits associated with morphology, phenology, and photosynthesis, which are considered important drivers of altitudinal adaptation. (3) Results: The quantitative trait loci (QTLs) for growth traits, phenology, needle morphology, and photosynthetic traits were subsequently detected. Similar to previous studies on conifers, most traits were controlled by multiple QTLs with small or moderate effects. Notably, we detected that one QTL for the crown area might be a type-A response regulator, a nuclear protein responsible for the cytokinin-induced shoot elongation. (4) Conclusion: The QTLs detected in this study include potentially important genomic regions linked to altitudinal adaptation in Sakhalin fir.
\end{abstract}

Keywords: altitude; chlorophyll fluorescence; crown area; linkage map; local adaptation; needle morphology; phenology; RAD-seq; TodoFirGene

\section{Introduction}

Local adaptation is an evolutionary process that is considered a home-site advantage, in which a genotype performs best in its native site [1]. As sessile organisms, plants are directly affected by the local climate, which is one of the most important drivers of adaptation [2]. However, a pairwise comparison between local and foreign plants revealed that local adaptation was observed in only $45 \%$ of the 1032 studied populations [3]. Hence, local adaptation is determined by the balance between gene flow and selection intensity [4]. For example, forest tree species with extensive gene flow generally exhibit local adaptation at a wide scale [5]. Selection drivers are usually complex because of a 
combination of climatic factors at distant sites, so the genetic basis of local adaptation in conifers is poorly understood.

Because the environmental conditions in an altitudinal gradient sharply change at a short spatial scale, these altitudinal gradients can be considered natural experiments [6]. High-altitude zones are generally characterized by a short growing season, high-intensity UV radiation, a low temperature, undeveloped soil, and heavy snow cover in combination with wind action [7]. Common garden data revealed that altitudinal clines for growth and bud phenology were present in conifers [8-10]. The clines from other common garden experiments also suggested the existence of local adaptation [11], but strict evidence was only obtained using reciprocal transplant experiments [12]. In herbaceous species, reciprocal transplant experiments at different altitudes demonstrated the local adaptation to native altitudinal zones [13,14]. However, for conifers, reciprocal transplant experiments at altitudinal gradients were rarely performed because of their large sizes and long generation times.

Elucidating the genetic basis of local adaptation is a hot topic in evolutionary biology [15]. Sakhalin fir (Abies sachalinensis) is an ideal organism for determining the genetic basis of altitudinal adaptation because the altitudinal clines for its growth and morphological traits were already revealed by common garden experiments [16] and provenance trials [17]. Reciprocal transplant experiments also demonstrated that the survival and growth rates of Sakhalin fir transplants were higher in planting sites close to their native altitudinal zones [18]. Additionally, segregated populations for altitudinal adaptation were already established for this species [19]. Using the segregated populations, several quantitative trait loci (QTLs) for phenology and growth traits have been identified in seedlings using linkage maps for this species [19]. Furthermore, the transcriptome database TodoFirGene (http:// plantomics.mind.meiji.ac.jp/todomatsu/), containing 158,542 de novo transcriptome sequences in 69,618 loci, was readily available and previously assisted in determining the function of genes in Sakhalin fir [20].

Sakhalin fir is an ecologically and economically important boreal coniferous species distributed across Sakhalin Island, the Southern Kuril Islands, and Hokkaido, northern Japan [21]. In Hokkaido, the contrasting region-dependent climatic conditions affect the genetic components and structure of this species [22]. Provenance trials revealed that four climatic variables, namely winter solar radiation, warmth index, maximum snow depth, and spring solar radiation, are essential for the growth of Sakhalin fir [23]. At the regional scale, the home-site advantage of this species was also detected in regions with distinct climates [24].

In the present study, we aimed to detect the QTLs for growth and bud phenology and to identify the eco-physiological traits that are genetically controlled by QTLs. We first measured the growth and eco-physiological traits that were potentially associated with altitudinal adaptation in a segregated population of Sakhalin fir and subsequently conducted QTL analysis using linkage maps constructed with newly developed single nucleotide polymorphism (SNP) markers to identify the genomic regions linked with traits involved in altitudinal adaptation.

\section{Materials and Methods}

\subsection{Plant Materials}

To establish a mapping population, we performed reciprocal pollination between two hybrids (high- $\times$ low-altitude genotypes) derived from different mother trees (A33 and A39) to avoid inbreeding depression (Table 1). Reciprocal crosses between P236 and P336 were performed in May 2011, and the cones were harvested in September 2011 [19]. In May 2012, the seeds were sown in the nursery of The University of Tokyo Hokkaido Forest (UTHF), Furano, Japan ( $43^{\circ} 30^{\prime} \mathrm{N}, 142^{\circ} 18^{\prime} \mathrm{E}, 230 \mathrm{~m}$ asl). After the seedlings were grown for two successive growing seasons, 252 saplings were transferred to long pots $(2320 \mathrm{cc})$ on 12 May 2015. The growing medium in the pots was a mixture of soft, solidified black soil 
(termed "kuroboku"), cocopeat (Top Co., Osaka, Japan), local volcanic ash soil, and bark compost in a 20:20:30:15 ratio $(v / v / v / v)$.

Table 1. The Sakhalin fir segregated population used for QTL analysis. Grandmother parent Clones (A33 and A39) are mother trees inhabiting high-altitude zones (1200 m). Clone 1-1 and Clone 1-2 are low-altitude genotypes derived from a pollen mixture collected from three genotypes living at low-altitudes $(530 \mathrm{~m})$.

\begin{tabular}{ccc}
\hline Pedigree & Female $\times$ Male Parent & Female $\times$ Male Parent \\
\hline Grandparents & Clone A33 $\times$ Clone C1- ${ }^{\dagger} \quad$ Clone A39 $\times$ Clone C1-2 ${ }^{\dagger}$ \\
Parents & Clone P336 $\times$ Clone P236, Clone P236 $\times$ Clone P336 \\
Parent size & P336 (height: 15.5 m, d.b.h.: $21.1 \mathrm{~cm})$ \\
& P236 (height: 16.4 m, d.b.h.: $23.4 \mathrm{~cm})$ \\
Crossing & May 2011 \\
Seed collection & September 2011 \\
Progeny & 252 \\
\hline
\end{tabular}

${ }^{\dagger}$ Clone 1-1 and Clone 1-2 are different genotypes confirmed by paternity analysis with nSSR and cpSSR markers. Height and diameter at breast height (d.b.h.) were measured in October 2018.

The saplings were grown for another two consecutive growing seasons at the Forestry Research Institute, Hokkaido Research Organization (HRO), Bibai, Japan $\left(43^{\circ} 17^{\prime}\right.$ N, $141^{\circ} 51^{\prime}$ $\mathrm{E}, 40 \mathrm{~m}$ asl). Considering the environmental heterogeneity among microhabitats (e.g., sun exposure), periodic rotation of the pots was performed. Additionally, the saplings were irrigated every morning to prevent drought stress. The soil was watered with Osmocote ${ }^{\circledR}$ Exact Standard 3-4M (N16-P9-K12) (ICL Specialty Fertilizers, Geldermalsen, The Netherlands) at the start of each growing season and with HYPONeX liquid (N6-P3360-K5) (HYPONeX Japan Co., Ltd., Osaka, Japan) during the latter part of the growing season, following the manufacturers' protocols.

The saplings were subsequently transplanted to a common garden that was established at the UTHF $\left(43^{\circ} 13^{\prime} \mathrm{N}, 142^{\circ} 24^{\prime} \mathrm{E}, 230 \mathrm{~m}\right.$ asl) on 27 April 2017. The saplings were planted in a randomized order at $2.0 \mathrm{~m}$ intervals. No irrigation or fertilization was performed for the transplants in the common garden, only weed control.

\subsection{Phenotyping}

The phenotype data of 15 functional traits, including four growth and 11 eco-physiological traits, for the 252 saplings in the segregation population were recorded (Table 2). On 4 October 2016, the stem diameter (D16, $\mathrm{mm})$ and height $(\mathrm{H} 16, \mathrm{~cm})$ of the saplings at the HRO were measured. After transplanting to the UTHF, the tree heights $(\mathrm{H} 17, \mathrm{~cm})$ were measured in the autumn of 2017, and images via photograph-based projection were captured from the top points of each tree. Then, the crown area $\left(\mathrm{CR} 17, \mathrm{~cm}^{2}\right)$ was estimated using LIA32 software (http:/ / www.agr.nagoya-u.ac.jp/ shinkan/LIA32/) (Figure 1).

\subsection{Characterization of Morphological Traits}

One-year-old needles were randomly collected from the middle portion of each branch and scanned using a digital scanner (MSC20; King Jim, Tokyo, Japan). The mean length and width of the needles (Lw_ratio) were determined using ImageJ software $(\mathrm{NIH}$, Bethesda, MD, USA; http:/ / rsbweb.nih.gov/ij/). The leaf mass per area (LMA, $\mathrm{g} \mathrm{cm}^{-2}$ ) was calculated by dividing the dry mass of 20 needles by the total needle area using ImageJ software. Following a previously used method [17], the stomatal density (SD, number $\mathrm{mm}^{-2}$ ) was estimated as the ratio of the number of stomata to the respective stomatal band area and the number of stomatal rows (SRN, number $\mathrm{mm}^{-1}$ ) was measured from the same images in a $0.88 \mathrm{~mm} \times 0.66 \mathrm{~mm}$ area. Transverse sections of the current season shoots of the saplings were photographed using a digital camera (DP71; Olympus, Tokyo, Japan) mounted on a light microscope (BX50; Olympus). The images were used to measure the ratio of bark width to xylem width (Bark_xy) and the ratio of normal wood width to reaction wood width (Norm_reac) using ImageJ software. 


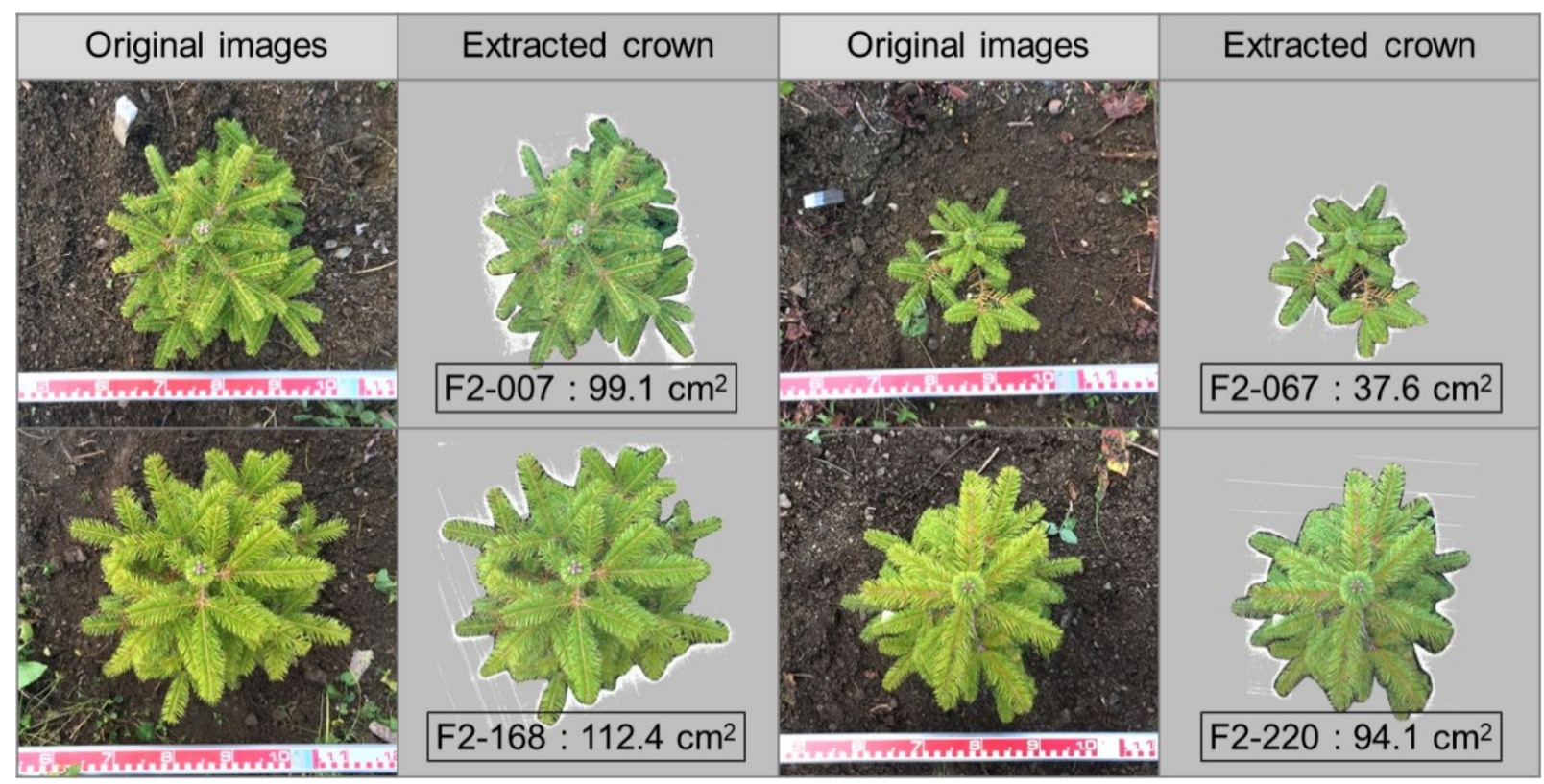

Figure 1. The original images taken via photograph-based projection (left) and the images of the individual plants with the calculated crown area based on the scale (right).

\subsection{Evaluation of Bud Phenology}

As a trait associated with plant phenology, the timing of bud flush (Bud_fl) was also recorded. On 6-29 May 2016, the status of the terminal bud in each pot sapling was monitored every two days. Following a previous study [19], Bud_fl was defined as the time point at which the initial emergence of needles from the terminal bud was observed. Hence, the number of days after 1 May was recorded as the Bud_fl.

\subsection{Evaluation of Freezing Tolerance}

To measure freezing tolerance, a freezing test was conducted on November 4, following the method of a previous study on Sakhalin fir [25]. Before the test, three healthy current-year needles were collected in the morning, placed in a thin plastic bag $(0.03 \mathrm{~mm})$, and incubated for $>3 \mathrm{~h}$ in a dark chamber maintained at $4{ }^{\circ} \mathrm{C}$ for dark acclimation. Each test was conducted by exposing the needles to the target temperature $\left(-20^{\circ} \mathrm{C}\right)$ for $5 \mathrm{~h}$, and then decreasing temperature at a rate of $12{ }^{\circ} \mathrm{Ch}^{-1}$ using a programmed freezer (SC-DF25K; Nippon Freezer Co., Tokyo, Japan). We measured the freezing damage to the needles after incubation for 2 days at $4{ }^{\circ} \mathrm{C}$, followed by an increase in temperature at a rate of $8{ }^{\circ} \mathrm{Ch}^{-1}$ using a pulse-amplitude modulated (PAM) chlorophyll fluorometer (Mini-PAM; Walz, Effeltrich, Germany). The maximum photochemical quantum yield of photosystem II (PSII; $\mathrm{Fv} / \mathrm{Fm}$ ) is negatively correlated with the extent of freezing damage, and thus, represents a reliable parameter for the assessment of freezing tolerance during autumn $[25,26]$. The $\mathrm{Fv} / \mathrm{Fm}$ values used as an index of freezing tolerance in this study were termed "Freez_tol".

\subsection{Measurement of Chlorophyll Fluorescence}

The saplings at the HRO were placed in a darkroom for 3 days. Chlorophyll fluorescence was then measured with a chlorophyll fluorometer (Junior-PAM; Walz, Effeltrich, Germany) using a detached leaf from the major axis of a current-season branch. The measurements were performed in a ventilated room, with $40 \mathrm{~Pa} \mathrm{CO}_{2}$ and $21 \mathrm{kPa} \mathrm{O}_{2}$ at $5{ }^{\circ} \mathrm{C}$. Saturation pulses from blue light-emitting diodes (LEDs; $>6000 \mu \mathrm{mol}$ photons $\mathrm{m}^{-2} \mathrm{~s}^{-1}$, $800 \mathrm{~ms}$ duration) were applied to determine the maximum chlorophyll fluorescence, with closed PSII centers in the dark (Fm) and under actinic light $\left(\mathrm{Fm}^{\prime}\right)$. The maximum photochemical quantum yield $(\mathrm{Fv} / \mathrm{Fm})$ and effective quantum yield $\left(\Phi_{\text {II }}\right)$ of PSII were calculated as $(\mathrm{Fm}-\mathrm{F} 0) / \mathrm{Fm}$ and $\left(\mathrm{Fm}^{\prime}-\mathrm{Fs}^{\prime}\right) / \mathrm{Fm}^{\prime}$, respectively [27], where $\mathrm{F} 0$ is the minimal chlorophyll 
fluorescence yield in the dark and Fs is the steady-state chlorophyll fluorescence level under actinic light from blue LEDs, with a wavelength peak at $445 \mathrm{~nm}$. Non-photochemical quenching (NPQ) was calculated as $\left(\mathrm{Fm}-\mathrm{Fm}^{\prime}\right) / \mathrm{Fm}^{\prime}$ [28]. Additionally, the PSII quantum yields $\Phi_{\mathrm{NPQ}}$ and $\Phi_{\mathrm{NO}}$ [29] that represent the regulated and non-regulated energy dissipation at the PSII centers, respectively, and add up to the unity of the photochemical quantum yield (i.e., $\Phi_{\mathrm{II}}+\Phi_{\mathrm{NPQ}}+\Phi_{\mathrm{NO}}=1$ ), were also calculated. The values of $\Phi_{\mathrm{NPQ}}$ and $\Phi_{\mathrm{NO}}$ were calculated as $\mathrm{Fs}^{\prime} / \mathrm{Fm}-\mathrm{Fs}^{\prime} / \mathrm{Fm}$ and Fs/Fm, respectively [30,31]. The Fv/Fm in dark-adapted leaves was measured overnight, and then the other parameters were measured under actinic light of $1500 \mu \mathrm{mol}$ photons $\mathrm{m}^{-2} \mathrm{~s}^{-1}$ for $2 \mathrm{~min}$.

Table 2. The 15 functional traits investigated in this study. The correlation between functional traits and altitude was demonstrated in previous studies of Sakhalin fir. The mean values, standard deviations (SD), and coefficients of variation $(\mathrm{CV}, \%)$ are presented. ${ }^{+}$Positive: LMA is generally highly correlated with leaf thickness.

\begin{tabular}{|c|c|c|c|c|c|c|}
\hline Category & $\begin{array}{l}\text { Trait } \\
\text { Abberviations }\end{array}$ & Trait Explanation & $\begin{array}{c}\text { Correlation } \\
\text { with Altitude }\end{array}$ & Reference & Mean (SD) & $\mathrm{CV}$ \\
\hline \multirow[t]{4}{*}{ Growth } & D16 & Stem diameter in 2016 & Negative & [16] & $35.01(8.595)$ & 0.246 \\
\hline & H16 & Height in 2016 & Negative & [16] & $11.39(2.298)$ & 0.202 \\
\hline & $\mathrm{H} 17$ & Height in 2017 & Negative & [16] & $45.15(10.94)$ & 0.242 \\
\hline & CR17 & Crown area in 2017 & Unknown & - & $106.3(39.43)$ & 0.371 \\
\hline \multirow[t]{2}{*}{ Phenology } & Bud_fl & Bud flush in 2016 & Unknown & - & $20.05(2.538)$ & 0.127 \\
\hline & Freez_tol & $\begin{array}{l}\text { Freezing tolerance in } \\
\text { Nov } 2016\end{array}$ & Positive & [25] & $0.387(0.209)$ & 0.541 \\
\hline \multirow[t]{6}{*}{ Morphology } & Lw_ratio & $\begin{array}{l}\text { Needle length/width } \\
\text { ratio }\end{array}$ & Negative & [17] & $19.21(3.277)$ & 0.171 \\
\hline & LMA & Leaf mass per area & Positive $^{\dagger}$ & [17] (Thickness) & $0.112(0.024)$ & 0.211 \\
\hline & Bark_xy & Bark-xylem length ratio & Positive & [17] & $0.452(0.042)$ & 0.093 \\
\hline & Norm_reac & $\begin{array}{l}\text { Normal/reaction wood } \\
\text { ratio }\end{array}$ & Negative & [17] & $0.604(0.113)$ & 0.188 \\
\hline & SD & Stoma density & Unknown & - & $289.8(54.34)$ & 0.188 \\
\hline & SRN & Number of stoma row & Positive & [17] & $11.80(1.583)$ & 0.134 \\
\hline \multirow[t]{3}{*}{ Photosynthesis } & $\Phi_{\mathrm{II}}$ & $\begin{array}{l}\text { Effective quantum yield } \\
\text { of PSII }\end{array}$ & Unknown & - & $0.308(0.043)$ & 0.138 \\
\hline & NPQ & $\begin{array}{l}\text { Non-photochemical } \\
\text { quenching }\end{array}$ & Unknown & - & $2.483(0.513)$ & 0.207 \\
\hline & $\Phi_{\mathrm{NO}}$ & $\begin{array}{l}\text { Non-regulated energy } \\
\text { dissipation at PSII } \\
\text { centers }\end{array}$ & Unknown & - & $0.202(0.024)$ & 0.117 \\
\hline
\end{tabular}

Determination of Relationships between Phenotypic Traits

The relationships between the functional traits were analyzed using $R$ version 3.6.1 [32]. The Pearson's correlation coefficients and $p$ values for correlations between functional traits were calculated. To simplify and visualize the strong correlations, a network plot was generated using the $\mathrm{R}$ package 'corrr' version 0.4.3 [33]. The proximity of the points was determined using multidimensional clustering, and the minimum coefficient value (in absolute terms) was set to 0.1 .

\subsection{Construction of Double-Digest Restriction Site-Associated DNA Sequencing (ddRAD-seq) Library}

A total of 252 individuals were included in ddRAD-seq experiment [34]. Compared with the original restriction site-associated DNA sequencing (RAD-seq) [35], ddRAD-seq effectively reduced the complexity of studying the large genome of conifers [36]. The total genomic DNA (250 ng) from each sample was digested with SphI and PstI, ligated with Y-shaped adaptors, and amplified by PCR using KAPA HiFi polymerase (KAPA Biosystems, Woburn, MA, USA). After PCR amplification with adapter-specific primer pairs (Access Array Barcode Library for Illumina Sequencers; Fluidigm, San Francisco, 
CA, USA), an equal amount of DNA from each sample was mixed and size-selected using BluePippin agarose gel cassettes (Sage Science, Beverly, MA, USA). The library fragments $(\sim 450 \mathrm{bp})$ were retrieved, and the quality of the library was checked using an Agilent 2100 Bioanalyzer with a high-sensitivity DNA chip (Agilent Technologies, Waldbronn, Germany). The library was sequenced using the Illumina ${ }^{\circledR}$ HiSeq X platform (Illumina, San Diego, CA, USA) to generate 150 bp long paired-end reads (see details in Supplementary Materials S1). The raw ddRAD-seq data were deposited in the DNA Data Bank of Japan (DDBJ) under accession number DRA012397.

\subsection{Genotyping}

Quality control, adapter trimming, and quality filtering of the ddRAD-seq raw data were performed using fastp program version 0.20 .0 [37]. A sliding window of 15 bases was used to filter reads with low-quality scores (Phred quality values $<10$ ). The high-quality ddRAD-seq data were processed using the ustacks, cstacks, sstacks, tsv2bam, and gstacks programs of Stacks software version 2.5 [38], following the Stacks manual for a de novo genetic mapping cross (http:/ / catchenlab.life.illinois.edu/stacks/manual/, accessed on 21 July 2021). This method builds catalogs from the parents of a mapping population only, which enables the exclusion of potential errors derived from the mapping progeny. The number of mismatches allowed between stacks within and between individuals was set to four (i.e., $\mathrm{M}$ and $\mathrm{n}$ options in ustacks and cstacks, respectively). The populations program in Stacks pipeline was used to retain the loci that were observed in $>80 \%$ of individuals in the mapping progeny. The retained loci were exported in JoinMap format via a cross pollination $(\mathrm{CP})$ mode using the same program to construct the linkage maps.

\subsection{Linkage Map Construction}

Two types of linkage maps (P336 and P236) were constructed based on the segregation patterns of the genetic markers, following the method of the previous study [19]. The P336 and P236 maps were comprised of the $\mathrm{aa} \times \mathrm{ab}$ and $\mathrm{ab} \times$ aa type markers, respectively. Markers that contained a large amount of missing data $(>20 \%)$ and showed significant deviation (chi-square test; $p<0.001$ ) from the expected Mendelian segregation ratio were excluded. Linkage analysis was conducted for the populations of cross pollinators (CP) with the regression mapping method using JoinMap v5.0 software [39]. Default settings were used for determining the recombination frequency.

\subsection{QTL Analysis}

QTL analysis was conducted using linear models with a regularized horseshoe prior to distribution, which can detect and assess relevant variables from a large number of irrelevant variables [40]. First, to reduce collinearity and redundancy among variables, one marker from a given pair of markers that were in close proximity $(<1 \mathrm{cM})$ and showed high correlation $(r>0.7)$ with other markers was removed prior to the analysis. Second, four chains were used to estimate the posterior distribution, and a total of 5000 iterations after the first 1000 iterations were discarded as burn-in. The convergence of the chains was confirmed using the Gelman-Rubin statistic $(\hat{R}<1.1)$. Third, the posterior distribution was estimated using the R package 'rstanarm' [41]. The global shrinkage parameter of the regularized horseshoe prior was set using the equation proposed by a previous study [40]:

$$
\frac{p 0}{D-p 0} \frac{1}{\sqrt{n}}
$$

where $p 0$ is the expected number of relevant variables, $D$ is the number of variables, and $n$ is the number of observations. For all traits, the value of $p 0$ was set to five because the QTLs of various tree species were known to exhibit small effects [42]. The sensitivity of the $p 0$ value for QTL detection was confirmed by arranging $p 0$ from 1 to 9 (Table S1). The default values of the regularized horseshoe prior in the R package 'rstanarm' were used for the remaining parameters. 
Fourth, given that the variables in the aforementioned model were highly correlated, the estimated marginals of the posterior distribution of the marker effects may be biased because of collinearity. To address this problem, a model selection method, projectionpredictive variable selection [43], was applied to the model. The model selection method uses a model that has the best predictive power (a reference model) to find a simpler model that has similar predictions as the reference model (predictive projection). The linear model described above was used as the reference model. Model selection was performed when the variables in the reference model contained significantly more information than the null model, which was confirmed by leave-one-out cross-validation [44]. When the marginal posterior distribution of the marker effects in the selected model did not contain zero in the $95 \%$ and $80 \%$ credible intervals, the markers were defined as significant and suggestive of QTLs, respectively. The contribution of each QTL was estimated by the coefficient of determination $\left(\mathrm{R}^{2}\right)$ of the simple regression; and the contribution was defined as the percentage variance explained (PVE) for a QTL. The QTL analysis and model selection were both performed using $\mathrm{R}$ version 3.6.1 [32]. The leave-one-out cross-validation procedure was performed using the R package 'loo' [45], while the model selection method was conducted using the R package 'projpred' [43].

\subsection{Candidate Gene Prediction}

Genes in the target QTL regions were predicted in the Sakhalin fir transcriptome database TodoFirGene [20] using the basic local alignment search tool (BLAST) nucleotide algorithm. The transcripts of the candidate genes were obtained from TodoFirGene and subsequently annotated using the Gene Ontology (GO) and Kyoto Encyclopedia of Genes and Genomes (KEGG; https:/ / www.kegg.jp/kegg/kegg2.html, accessed on 16 July 2021) databases.

\section{Results}

\subsection{Phenotypic Traits}

Based on the results of previous studies, these traits are potentially associated with altitudinal adaptation (Table 1). The mean values, standard deviations, and coefficients of variation for the 15 functional traits are presented in Table 1 . The distribution of each phenotype was observed to have a modal shape (Figure S1). The network analysis revealed the relationships among the functional traits investigated, in which two clusters were identified for the growth and photosynthetic traits (Figure 2). Furthermore, growth-related traits were discovered to be positively correlated with Bud_fl, whereas Lw_ratio was negatively correlated with Bark_xy ratio. Pairwise correlations between functional traits using Pearson's correlation coefficients showed significant negative correlations between certain photosynthetic traits, such as $\Phi_{\mathrm{II}}$ vs. NPQ $(r=-0.63, p<0.001)$ and NPQ vs. $\Phi_{\mathrm{NO}}$ $(r=-0.89, p<0.001)$ (Figure S2). However, a positive correlation was observed between $\Phi_{\mathrm{II}}$ and $\Phi_{\mathrm{NO}}(r=0.24)$, whereas strong and highly positive correlations were observed between growth traits $(r>0.5)$.

\subsection{Linkage Map Construction and QTL Detection}

A total of 486 and 516 markers were mapped to 12 linkage groups (LG) in the P336 and P236 maps, respectively. For the P336 and P236 maps, the total lengths were $1986.2 \mathrm{cM}$ and $1932.8 \mathrm{cM}$, respectively, whereas the average distances between adjacent markers were $4.1 \mathrm{cM}$ and $3.7 \mathrm{cM}$, respectively. The maximum marker gaps for P336 map and P236 map were $29.8 \mathrm{cM}$ and $27.3 \mathrm{cM}$, respectively (Table 3 ). 


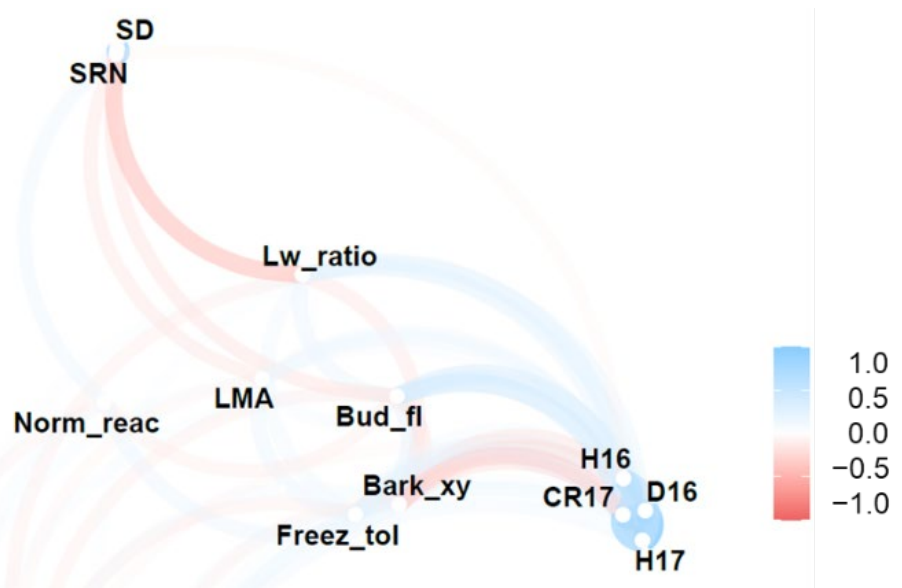

$N P Q$

Figure 2. The relationships between functional traits based on network analysis. D16: Stem diameter in 2016, H16: Height in 2016, H17: Height in 2017, CR17: Crown area in 2017, Bud_fl: Bud flush in 2016, Freez_tol: Freezing tolerance in Nov 2016, Lw_ratio: Needle length/width ratio, LMA: Leaf mass per area, Bark_xy: Bark-xylem length ratio, Norm_reac: Normal/reaction wood ratio, SD: Stoma density, SRN: Number of stoma row, $\Phi_{I I}$ : Effective quantum yield of PSII, NPQ: Non-photochemical quenching, $\Phi_{\mathrm{NO}}$ : Non-regulated energy dissipation at PSII centers.

Table 3. The length of and the number of markers in each linkage group.

\begin{tabular}{|c|c|c|c|c|c|}
\hline Map & $\begin{array}{l}\text { Linkage } \\
\text { Group }\end{array}$ & Marker & $\begin{array}{l}\text { Length } \\
\text { (cM) }\end{array}$ & $\begin{array}{c}\text { Average Distance } \\
\text { between Markers (cM) }\end{array}$ & Gap (Max.) \\
\hline \multirow[t]{13}{*}{ P336 } & 1 & 42 & 154.4 & 3.7 & 17.3 \\
\hline & 2 & 30 & 174.9 & 5.8 & 21.8 \\
\hline & 3 & 31 & 145.6 & 4.7 & 17.6 \\
\hline & 4 & 50 & 192.9 & 3.9 & 22.2 \\
\hline & 5 & 28 & 128.6 & 4.6 & 15.8 \\
\hline & 6 & 40 & 147.5 & 3.7 & 29.8 \\
\hline & 7 & 44 & 208.1 & 4.7 & 18.0 \\
\hline & 8 & 45 & 162.5 & 3.6 & 14.1 \\
\hline & 9 & 51 & 151.3 & 3.0 & 10.1 \\
\hline & 10 & 36 & 192.6 & 5.4 & 26.3 \\
\hline & 11 & 45 & 151.8 & 3.4 & 20.9 \\
\hline & 12 & 44 & 176.0 & 4.0 & 27.8 \\
\hline & Total & 486 & 1986.2 & 4.1 & 29.8 \\
\hline \multirow[t]{13}{*}{ P236 } & 1 & 51 & 185.0 & 3.6 & 18.7 \\
\hline & 2 & 45 & 189.5 & 4.2 & 27.3 \\
\hline & 3 & 35 & 131.7 & 3.8 & 13.7 \\
\hline & 4 & 44 & 180.7 & 4.1 & 19.9 \\
\hline & 5 & 31 & 126.6 & 4.1 & 17.4 \\
\hline & 6 & 39 & 141.3 & 3.6 & 22.2 \\
\hline & 7 & 54 & 180.1 & 3.3 & 18.5 \\
\hline & 8 & 43 & 185.8 & 4.3 & 18.5 \\
\hline & 9 & 43 & 155.2 & 3.6 & 19.0 \\
\hline & 10 & 44 & 166.1 & 3.8 & 18.3 \\
\hline & 11 & 43 & 136.4 & 3.2 & 12.5 \\
\hline & 12 & 44 & 154.7 & 3.5 & 13.7 \\
\hline & Total & 516 & 1932.8 & 3.7 & 27.3 \\
\hline
\end{tabular}


Three significant and 11 suggestive QTLs were detected in the P336 map, whereas five significant and 10 suggestive QTLs were observed in the P236 map (Table 4; Figure 3). Significant QTLs for $\Phi_{\mathrm{NO}}$ and CR17 and for $\Phi_{\mathrm{NO}}, \mathrm{H} 16, \mathrm{H} 17$, and CR17 were detected in the P336 and P236 maps, respectively. In addition, suggestive QTLs for NPQ, Bud_fl, Freez_tol, Lw_ratio, H16, H17, and CR17 and for NPQ, Bud_fl, Lw_ratio, D16, H17, and CR17 were detected in the P336 and P236 maps, respectively. A significant QTL (Locus \#2055) was detected for NPQ and $\Phi_{\mathrm{NO}}$ in both linkage maps. In the P236 map, Locus \#12865 was discovered as a significant QTL for CR17 and a suggestive QTL for D16, H16, and H17 (Figure 3). In the P336 map, suggestive QTLs for Bud_fl and Freez_tol were co-located in LG5 within a $10 \mathrm{cM}$ distance (Figure 3).

Table 4. The QTLs detected for each functional trait. The marker position (Pos.) and percentage variance explained (PVE) of each QTL are shown. The level of significance is presented in the Sig. column, with * $80 \%$ and $* * 95 \%$ confidence intervals.

\begin{tabular}{|c|c|c|c|c|c|c|}
\hline Category & Trait & Locus & Map-LG & Pos (cM) & Sig. & PVE (\%) \\
\hline \multirow[t]{12}{*}{ Growth } & D16 & $\# 12865$ & P236-LG7 & 102.8 & * & 6.70 \\
\hline & H16 & \#10164 & P336-LG9 & 88.7 & $*$ & 4.27 \\
\hline & H16 & $\# 12865$ & P236-LG7 & 102.8 & $* *$ & 9.17 \\
\hline & H17 & $\# 10758$ & P336-LG4 & 50.7 & $*$ & 4.16 \\
\hline & H17 & \#10541 & P336-LG9 & 100.9 & * & 4.57 \\
\hline & $\mathrm{H} 17$ & $\# 10758$ & P236-LG4 & 47.5 & * & 4.16 \\
\hline & $\mathrm{H} 17$ & \#12865 & P236-LG7 & 102.8 & $* *$ & 7.81 \\
\hline & CR17 & $\# 6809$ & P336-LG10 & 95.9 & $*$ & 2.62 \\
\hline & CR17 & \#10829 & P336-LG10 & 144.6 & $* *$ & 5.66 \\
\hline & CR17 & $\# 1970$ & P336-LG11 & 45.2 & $*$ & 5.45 \\
\hline & CR17 & \#10541 & P336-LG9 & 100.9 & * & 4.28 \\
\hline & CR17 & $\# 6809$ & P236-LG10 & 81.5 & * & 2.62 \\
\hline \multirow[t]{3}{*}{ Phenology } & Bud_fl & \#6899 & P336-LG5 & 117.2 & * & 6.07 \\
\hline & Bud_fl & \#6899 & P236-LG5 & 105.4 & * & 6.07 \\
\hline & Freez_tol & \#25432 & P336-LG5 & 123.8 & * & 7.40 \\
\hline \multirow[t]{3}{*}{ Morphology } & Lw_ratio & \#24342 & P336-LG3 & 60.0 & * & 5.96 \\
\hline & Lw_ratio & \#7510 & P336-LG6 & 82.0 & * & 2.97 \\
\hline & Lw_ratio & \#30964 & P236-LG7 & 5.2 & * & 5.28 \\
\hline \multirow[t]{6}{*}{ Photosynthesis } & $\mathrm{NPQ}$ & \#2055 & P336-LG7 & 92.6 & * & 6.12 \\
\hline & NPQ & \#2055 & P236-LG7 & 80.1 & $*$ & 6.12 \\
\hline & $\Phi_{\mathrm{NO}}$ & \#2055 & P336-LG7 & 92.6 & $* *$ & 9.32 \\
\hline & $\Phi_{\mathrm{NO}}$ & \#27288 & P336-LG9 & 117.1 & $* *$ & 7.24 \\
\hline & $\Phi_{\mathrm{NO}}$ & \#2055 & P236-LG7 & 80.1 & $* *$ & 9.32 \\
\hline & $\Phi_{\mathrm{NO}}$ & \#27288 & P236-LG9 & 121.3 & $* *$ & 7.24 \\
\hline
\end{tabular}

\subsection{Candidate Gene Prediction}

Out of 16 unique QTLs, eight were found in the transcripts of TodoFirGene (Table S2). Among the eight QTLs, locus \#1970, which is associated with CR17, was annotated as a typeA Arabidopsis response regulator (type-A ARR) of phosphorelay signal transduction system and a type-A ARR of cytokinin signaling in the GO and KEGG databases, respectively. The sequence of locus \#1970 was shown in Supplementary Materials S2. 

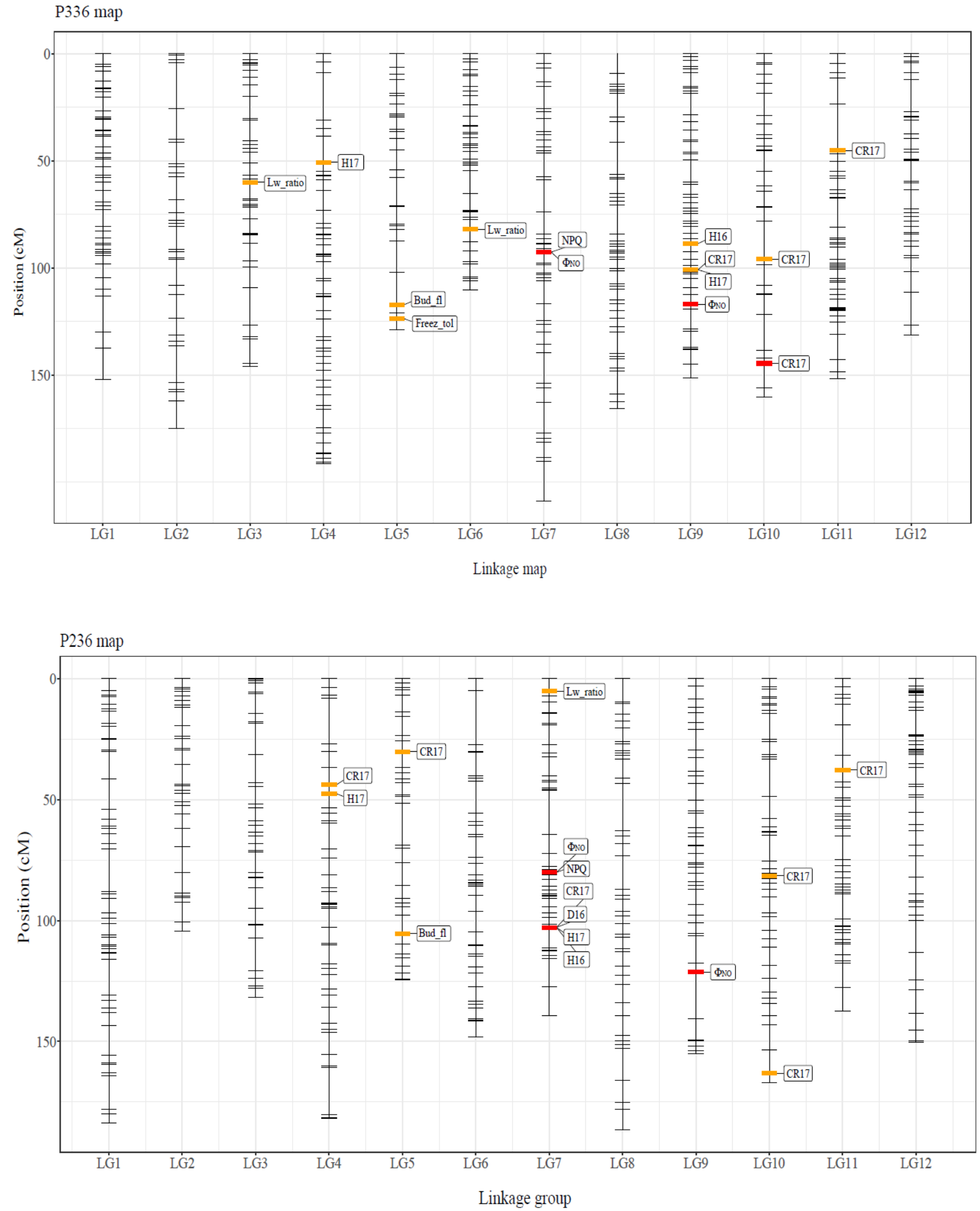

Figure 3. QTL mapping for the 15 functional traits. P336 and P236 maps were demonstrated in the upper and lower panels, respectively. 


\section{Discussion}

\subsection{Segregated Population and Linkage Maps}

Long generation times and the outbred mating system of conifers were used to construct a suitable mapping population. Because several pedigrees are available for important traits, including height growth and wood properties, in a tree breeding program, secondgeneration populations were used for QTL mapping [46-49]. However, $F_{1}$ pedigrees have been used for QTL mapping of eco-physiological studies in the evolutionary biology of conifers [50,51]. In the present study, we used segregated populations based on control crosses with four different grandparent trees with distinct genetic backgrounds (Table 1) [19]. Furthermore, altitudinal adaptation was clearly demonstrated by a reciprocal transplant experiment [18]. Our studies are limited by the number of pedigrees, locations and sample replications. Nevertheless, the segregated populations were constructed by a control cross between $\mathrm{F}_{1}$ hybrids with two contrasting ecotypes (high-altitude and lowaltitude grandparents), which might be useful to clarify the genetic basis of altitudinal adaptation in conifers as described in a previous paper [19].

The linkage maps were saturated, with a $10 \mathrm{cM}$ interval between nearest markers. The average distance between nearest markers detected in this study (approximately $4 \mathrm{cM}$; Table 3) was also comparable with that in previous studies $[46,48,50,52]$. The maximum marker gap distance in this study (approximately $20 \mathrm{cM}$ ) was also similar to that in a previous study [51]. Recently, high-density linkage maps with an average distance between nearest markers of less than $1 \mathrm{cM}$ have been constructed with several thousand SNP markers $[47,53]$. In addition, gene-based markers have been applied to obtain functional information [50]. The reconstruction of the linkage map using gene-based markers might improve the accuracy of QTL mapping in future studies.

\subsection{Growth Traits}

The segregation populations reflected the broad growth variations along an altitudinal gradient. The coefficient of variation (CV) for the heights of 4-year-old Sakhalin fir seedlings was $\sim 0.20$, which is similar to the CV value (0.19) reported for 4-year-old seedlings in the provenance trials [16]. The growth traits analyzed in the present study were mostly controlled by several QTLs with small or moderate effects (PVE: 2.6-9.3\%) (Figure 3; Table 4). This result corroborates that of a previous study on Sakhalin fir, in which several QTLs with small or moderate effects (PVE: 3.8-7.4\%) were detected for H17 and D16 at the early stage. QTLs with small or moderate effects on growth traits have also been detected in other conifers [46-49].

The crown area and width seem to be a good indicator for growth. In the present study, CR17 was measured using the digital images for growth traits (Figure 1). The number of QTLs for CR17 was the highest among the traits examined in this study; five exhibited moderate effects (PVE > 5\%; Table 2; Figure 3). The QTLs for crown width detected in this study have also been reported in other conifers [47]. Notably, Locus \#1970 of the QTLs for CR17 was annotated as a type-A Arabidopsis Response Regulator (type-A ARR; Table S2), which functions as a key node in the integration of ethylene and cytokinin signaling to regulate plant responses and shoot elongation in Arabidopsis thaliana [54]. Type-A response regulators (Type-A RRs) play an important role in cytokinin-induced adventitious shoot formation in Pinaceae (Pinus pinea) [55]. Furthermore, it is known that crown size is determined by the expansion and division of cells in the apical and cambial meristems. Yang et al. [47] previously detected QTLs for growth traits, including crown width, in the interspecific hybrid clones of Taxodium species, which is widely grown in southern China for economic and ecological purposes, and reported that the three markers were annotated as a leucine-rich repeat receptor-like kinase $(L R R-R L K)$ gene, which is specifically expressed in the vascular tissues and is vital for stem growth. 


\subsection{Eco-Physiological Traits}

Among the morphological traits, three QTLs were detected for needle length/width ratio (Table 4; Figure 3). The provenance trial of Sakhalin fir demonstrated that the length/width ratio was negatively correlated with the altitude of seed source [17]. However, no studies related to the QTLs for needle length/width ratio were available for other conifers. For example, needle length was only investigated in Pinus elliottii var. elliottii $\times$ P. caribaea var. hondurensis hybrids [48]. In Populus and European beech, a major QTL for leaf length/width ratio was identified using linkage mapping [56,57]. No QTLs were detected for the other morphological traits (i.e., Norm_reac, LMA, SD, and SRN) examined in the present study. However, altitudinal clines have been detected in mature stands based on a provenance trial [17], suggesting that these morphological trends may have emerged at an advanced life-cycle stage.

Additionally, QTLs were detected for Bud_fl and Freez_tol (Table 4; Figure 3). A QTL for Bud_fl was also detected in a previous study of Sakhalin fir [17]. Bud phenology traits generally exhibit high heritability and are often controlled by several QTLs. A positive correlation between Bud_fl and growth traits was observed, indicating that the saplings with later Bud_fl tended to be larger in growth, which supports the data of a previous study on Sakhalin fir [19]. The Freez_tol was also found to be positively correlated with growth traits (Figure 2; Figure S2). The timing of acquiring Freez_tol was associated with the altitudinal adaptation of Sakhalin fir $[25,58]$. The locations of the QTLs for Bud_flush and Freez_tol were relatively close in the P336 map-LG5, with a distance of $\sim 10 \mathrm{cM}$ (Figure 3). QTL clusters for height, density, and wood properties were also previously reported in Douglas fir [52]. These QTL clusters potentially represent pleiotropic effects or may be evidence for clusters of linked genes [59]. Because generating large amounts of meaningful data related to photosynthesis is easy, the data on chlorophyll fluorescence, including $\Phi_{\text {II }}$, $\mathrm{NPQ}$, and $\Phi_{\mathrm{NO}}$, can be directly applied to eco-physiological studies [60]. $\Phi_{\mathrm{II}}$ is an indicator of photosynthetic activity [29]. Because NPQ is associated with functional traits required to avoid photoinhibition [61] and $\Phi_{\mathrm{NO}}$ represents the non-regulated energy dissipation at the PSII centers, these parameters might be important for trees living in high-altitude zones. Although we did not detect any QTLs for $\Phi_{\text {II }}$ QTLs for NPQ and $\Phi_{\text {NO }}$ were readily observed (Table 4; Figure 3). In general, the inhibition of photosynthesis by low temperature results in a considerable excess of energy, leading to photodamage. Specifically, selection to avoid photoinhibition should be stronger than that in low-altitude zones. Therefore, energy dissipation of heat and non-regulated energy might be essential for adaptation in high-altitudinal zones.

\section{Conclusions}

To elucidate the genetic basis of altitudinal adaptation in Sakhalin fir, a QTL analysis with linkage maps was conducted for 15 functional traits potentially associated with altitudinal adaptation. Similar to a previous study, QTLs with moderate PVE were detected for growth traits; ten were linked to CR17. Notably, one QTL for CR17 might function as a type-A RR, which plays an important role in cytokinin-induced shoot elongation. The QTLs for morphological traits (needle length/width ratio) and phenology (Bud_fl and Freez_tol) were also identified. Furthermore, our results suggest that two significant QTLs may be genetically controlling $\Phi_{\mathrm{NO}}$ in Sakhalin fir. Reproducibility of the QTLs detected in the present study should be examined in the future because we conducted the analysis with a single pedigree, in a single location, and there was no replication of segregated populations. Nevertheless, we believe that these findings might be an important initial step for detecting candidate genes for altitudinal adaptation in conifers because altitudinal adaptation has been demonstrated by a reciprocal transplant experiment [18], and a segregation population was produced by a control cross between $\mathrm{F}_{1}$ hybrids with grandparents that were high-altitude and low-altitude genotypes [19]. 
Supplementary Materials: The following are available online at https:/ /www.mdpi.com/article/ 10.3390/genes12081110/s1; Supplementary Materials S1. Protocol of ddRAD-seq; Supplementary Materials S2. Sequence of \#1970 Loci Derived from ddRAD-seq; Figure S1, Histograms of the functional traits measured in the present study; Figure S2, Correlations among functional traits; Table S1, Model comparison in case of $p 0=1,3,5,7$ and 9 [62]. Model comparison in case of $p 0=1$, 3, 5, 7 and 9 [62]. * elpd-se $>0,{ }^{* *}$ elpd-se $>$ se-diff, other traits were not significant between the null model and the full model, Table S2. Description of candidate genes underlying QTLs in the present study.

Author Contributions: Conceptualization, S.G., W.I. and H.T.; methodology, W.I., H.I., M.K., K.U., H.M., H.K.-K., H.I. and S.G.; software, H.M.; validation, K.U., H.M., H.K.-K., H.I. and S.G.; formal analysis, K.U., H.K.-K., and H.I.; investigation, W.I., M.K., H.T. and S.G.; resources, S.G.; data curation, H.M.; writing—original draft preparation, S.G.; writing—review and editing, S.G., W.I., H.M., M.K., H.T., K.U., H.K.-K. and H.I.; visualization, W.I., H.M., H.K.-K. and S.G.; project administration, S.G.; funding acquisition, S.G. All authors have read and agreed to the published version of the manuscript.

Funding: This research was funded by JSPS KAKENHI 16H02554, 16H06279 (PAGS), and 20H03021.

Institutional Review Board Statement: Not applicable.

Informed Consent Statement: Not applicable.

Data Availability Statement: The raw ddRAD-seq data generated in this study were deposited in the DNA Data Bank of Japan (DDBJ) under accession number DRA012397.

Acknowledgments: The authors thank N. Kimura, S. Fukuoka, Y. Ando, M. Ando, Y. Nakatsubo, and K. Uchishiba for managing the nursery, transplanting the saplings to the common garden of the University of Tokyo Hokkaido Forest (UTHF), and assisting with the sample collection and measurements. We are grateful to T. Sugai, H. Kanno, and the technical staff of the Hokkaido Research Organization (HRO) for their assistance with managing the pot experiments at the HRO and measuring the functional traits. We also appreciate the helpful suggestions of Y. Hisamoto regarding the annotation of the candidate genes.

Conflicts of Interest: The authors declare no conflict of interest.

\section{References}

1. Kawecki, T.J.; Ebert, D. Conceptual issues in local adaptation. Ecol. Lett. 2004, 7, 1225-1241. [CrossRef]

2. Aitken, S.N.; Yeaman, S.; Holliday, J.A.; Wang, T.; Curtis-McLane, S. Adaptation, migration or extirpation: Climate change outcomes for tree populations. Evol. Appl. 2008, 1, 95-111. [CrossRef] [PubMed]

3. Leimu, R.; Fischer, M. A meta-analysis of local adaptation in plants. PLoS ONE 2008, 3, e4010. [CrossRef] [PubMed]

4. Savolainen, O.; Pyhäjärvi, T.; Knürr, T. Gene flow and local adaptation in trees. Annu. Rev. Ecol. Evol. Syst. 2007, 38, 595-619. [CrossRef]

5. Reich, P.B.; Oleksyn, J. Climate warming will reduce growth and survival of Scots pine except in the far north. Ecol. Lett. 2008, 11, 588-597. [CrossRef]

6. Körner, C. The use of 'altitude' in ecological research. Trends Ecol. Evol. 2007, 22, 569-574. [CrossRef]

7. Körner, C. Alpine Plant Life-Functional Plant Ecology of High Mountain Ecosystems; Springer: Berlin/Heidelberg, Germany, 2003.

8. Oleksyn, J.; Modrzýnski, J.; Tjoelker, M.; Zytkowiak, R.; Reich, P.B.; Karolewski, P. Growth and physiology of Picea abies populations from elevational transects: Common garden evidence for altitudinal ecotypes and cold adaptation. Funct. Ecol. 1998, 12, 573-590. [CrossRef]

9. Rehfeldt, G.E.; Ying, C.C.; Spittlehouse, D.L.; Hamilton, D.A., Jr. Genetic responses to climate in Pinus contorta: Niche breadth, climate change, and reforestation. Ecol. Monog. 1999, 69, 375-407. [CrossRef]

10. Sáenz-Romero, C.; Guzmán-Reyna, R.R.; Rehfeldt, G.E. Altitudinal genetic variation among Pinus oocarpa populations in Michoacán, Mexico: Implications for seed zoning, conservation, tree breeding and global warming. For. Ecol. Manag. 2006, 229, 340-350. [CrossRef]

11. White, T.; Adams, W.; Neale, D. Forest Genetics; CABI Pub.: Wallingford, Oxfordshire, UK; Cambridge, MA, USA, 2007 ; p. 682.

12. Hufford, K.M.; Mazer, S.J. Plant ecotypes: Genetic differentiation in the age of ecological restoration. Trends Ecol. Evol. 2003, 18, 147-155. [CrossRef]

13. Clausen, J.; Keck, D.D.; Hiesey, W.M. Regional differentiation in plant species. Am. Nat. 1941, 75, 231-250. [CrossRef]

14. Clausen, J.; Keck, D.D.; Hiesey, W.M. Heredity of geographically and ecologically isolated races. Amer. Nat. 1947, 81, 114-133. [CrossRef] [PubMed] 
15. Savolainen, O.; Lascoux, M.; Merilä, J. Ecological genomics of local adaptation. Nat. Rev. Genet. 2013, 14, 807-820. [CrossRef] [PubMed]

16. Kurahashi, A.; Hamaya, T. Variation of morphological characters and growth response of Sakhalin fir (Abies sachalinensis) in different altitude. Bull. Tokyo Univ. For. 1981, 71, 101-151.

17. Taneda, H.; Funayama-Noguchi, S.; Mayr, S.; Goto, S. Elevational adaptation of morphological and anatomical traits by Sakhalin fir (Abies sachalinensis). Trees 2020, 34, 507-520. [CrossRef]

18. Ishizuka, W.; Goto, S. Modeling intraspecific adaptation of Abies sachalinensis to local altitude and responses to global warming, based on a 36-year reciprocal transplant experiment. Evol. Appl. 2012, 5, 229-244. [CrossRef]

19. Goto, S.; Kajiya-Kanegae, H.; Ishizuka, W.; Kitamura, K.; Ueno, S.; Hisamoto, Y.; Kudoh, H.; Yasugi, M.; Nagano, A.J.; Iwata, H Genetic mapping of local adaptation along the altitudinal gradient in Abies sachalinensis. Tree Genet. Gen. 2017, 13, 104. [CrossRef]

20. Ueno, S.; Nakamura, Y.; Kobayashi, M.; Terashima, S.; Ishizuka, W.; Uchiyama, K.; Tsumura, Y.; Yano, K.; Goto, S. TodoFirGene: Developing transcriptome resources for genetic analysis of Abies sachalinensis. Plant Cell Physiol. 2018, 59, 1276-1284. [CrossRef]

21. Yamazaki, T. Pinaceae. In Flora of Japan: Pteridophyta and Gymnospermae; Kodansha: Tokyo, Japan, 1995; pp. $266-277$.

22. Kitamura, K.; Uchiyama, K.; Ueno, S.; Ishizuka, W.; Tsuyama, I.; Goto, S. Geographical gradients of genetic diversity and differentiation among the southernmost marginal populations of Abies sachalinensis revealed by EST-SSR polymorphism. Forests 2020, 11, 233. [CrossRef]

23. Tsuyama, I.; Ishizuka, W.; Kitamura, K.; Taneda, H.; Goto, S. Ten Years of provenance trials and application of Multivariate Random Forests predicted the most preferable seed source for silviculture of Abies sachalinensis in Hokkaido, Japan. Forests 2020, 11, 1058. [CrossRef]

24. Ishizuka, W.; Kon, H.; Kita, K.M.K.; Goto, S. Local adaptation to contrasting climatic conditions in Sakhalin fir (Abies sachalinensis) revealed by long-term provenance trials. Ecol. Res. 2021. [CrossRef]

25. Ishizuka, W.; Ono, K.; Hara, T.; Goto, S. Use of intraspecific variation in thermal responses for estimating an elevational cline in the timing of cold hardening in a sub-boreal conifer. Plant. Biol. 2015, 17, 177-185. [CrossRef] [PubMed]

26. Lindgren, K.; Hällgren, J.-E. Cold acclimation of Pinus contorta and Pinus sylvestris assessed by chlorophyll fluorescence. Tree Physiol. 1993, 13, 97-106. [CrossRef]

27. Genty, B.; Briantais, J.-M.; Baker, N.R. The relationship between the quantum yield of photosynthetic electron transport and quenching of chlorophyll fluorescence. Biochim. Biophys. Acta (BBA)-Gen. Subj. 1989, 990, 87-92. [CrossRef]

28. Bilger, W.; Björkman, O. Role of the xanthophyll cycle in photoprotection elucidated by measurements of light-induced absorbance changes, fluorescence and photosynthesis in leaves of Hedera canariensis. Photosynth. Res. 1990, 25, 173-185. [CrossRef] [PubMed]

29. Kramer, D.M.; Johnson, G.; Kiirats, O.; Edwards, G.E. New fluorescence parameters for the determination of Q A redox state and excitation energy fluxes. Photosynth. Res. 2004, 79, 209. [CrossRef]

30. Hendrickson, L.; Furbank, R.T.; Chow, W.S. A simple alternative approach to assessing the fate of absorbed light energy using chlorophyll fluorescence. Photosynth. Res. 2004, 82, 73. [CrossRef] [PubMed]

31. Klughammer, C.; Schreiber, U. Complementary PS II quantum yields calculated from simple fluorescence parameters measured by PAM fluorometry and the Saturation Pulse method. PAM Appl. Notes 2008, 1, 201-247.

32. R Core Team. R: A Language and Environment for Statistical Computing; R Foundation for Statistical Computing: Vienna, Austria, 2020; Available online: https: / / www.R-project.org/ (accessed on 15 July 2021).

33. Kuhn, M.; Jackson, S.; Cimentada, J. Corrr: Correlations in R. R Package Version 0.4.3. 2020. Available online: https:/ /CRAN.Rproject.org / package=corrr (accessed on 15 June 2021).

34. Peterson, B.K.; Weber, J.N.; Kay, E.H.; Fisher, H.S.; Hoekstra, H.E. Double digest RADseq: An inexpensive method for de novo SNP discovery and genotyping in model and non-model species. PLoS ONE 2012, 7, e37135.

35. Baird, N.A.; Etter, P.D.; Atwood, T.S.; Currey, M.C.; Shiver, A.L.; Lewis, Z.A.; Selker, E.U.; Cresko, W.A.; Johnson, E.A. Rapid SNP discovery and genetic mapping using sequenced RAD markers. PLoS ONE 2008, 3, e3376. [CrossRef]

36. Parchman, T.L.; Jahner, J.P.; Uckele, K.A.; Galland, L.M.; Eckert, A.J. RAD-seq approaches and applications for forest tree genetics. Tree Genet. Gen. 2018, 14, 1-25. [CrossRef]

37. Chen, S.; Zhou, Y.; Chen, Y.; Gu, J. fastp: An ultra-fast all-in-one FASTQ preprocessor. Bioinformatics 2018, 34, i884-i890. [CrossRef]

38. Rochette, N.C.; Rivera-Colón, A.G.; Catchen, J.M. Stacks 2: Analytical methods for paired-end sequencing improve RADseq-based population genomics. Mol. Ecol. 2019, 28, 4737-4754. [CrossRef] [PubMed]

39. Van Ooijen, J. Joinmap 5, Software for the Calculation of Genetic Linkage Maps in Experimental Populations of Diploid Species; Kyazma, B.V.: Wageningen, The Neitherland.

40. Piironen, J.; Vehtari, A. Sparsity information and regularization in the horseshoe and other shrinkage priors. Ele. J. Stat. 2017, 11, 5018-5051. [CrossRef]

41. Goodrich, B.; Gabry, J.; Ali, I.; Brilleman, S. Rstanarm: Bayesian applied regression modeling via Stan. R Package Version 2018, 2,1758 .

42. Neale, D.B.; Kremer, A. Forest tree genomics: Growing resources and applications. Nat. Rev. Genet. 2011, 12, 111-122. [CrossRef]

43. Piironen, J.; Paasiniemi, M.; Vehtari, A. Projective inference in high- dimensional problems: Prediction and feature selection. Ele. J. Stat. 2020, 14, 2155-2197.

44. Vehtari, A.; Gelman, A.; Gabry, J. Practical Bayesian model evaluation using leave-one-out cross-validation and WAIC. Stat. Comput. 2017, 27, 1413-1432. [CrossRef] 
45. Vehtari, A.; Gelman, A.; Gabry, J. Loo: Efficient leave-one-out cross-validation and WAIC for Bayesian models. $R$ Package Version 2018, 2, 1003.

46. Brown, G.R.; Bassoni, D.L.; Gill, G.P.; Fontana, J.R.; Wheeler, N.C.; Megraw, R.A.; Mark, F.; Davis, M.F.; Sewell, M.M.; Tuskan, G.A.; et al. Identification of quantitative trait loci influencing wood property traits in loblolly pine (Pinus taeda L.). III. QTL verification and candidate gene mapping. Genetics 2003, 164, 1537-1546. [CrossRef]

47. Yang, Y.; Xuan, L.; Yu, C.; Wang, Z.; Xu, J.; Fan, W.; Guo, J.; Yin, Y. High-density genetic map construction and quantitative trait loci identification for growth traits in (Taxodium distichum var. distichum $\times$ T. mucronatum) $\times$ T. mucronatum. BMC Plant. Biol. 2018, 18, 1-14. [CrossRef] [PubMed]

48. Yang, H.; Liu, T.; Xu, B.; Liu, C.; Zhao, F.; Huang, S. QTL detection for growth and form traits in three full-sib pedigrees of Pinus elliottii var. elliottii $\times$ P. caribaea var. hondurensis hybrids. Tree Genet. Gen. 2015, 11, 1-9. [CrossRef]

49. Mori, H.; Ueno, S.; Ujino-Ihara, T.; Fujiwara, T.; Yamashita, K.; Kanetani, S.; Endo, R.; Matsumoto, A.; Uchiyama, K.; Matsui, Y. Mapping quantitative trait loci for growth and wood property traits in Cryptomeria japonica across multiple environments. Tree Genet. Gen. 2019, 15, 1-15. [CrossRef]

50. Pelgas, B.; Bousquet, J.; Meirmans, P.G.; Ritland, K.; Isabel, N. QTL mapping in white spruce: Gene maps and genomic regions underlying adaptive traits across pedigrees, years and environments. BMC Genom. 2011, 12, 145. [CrossRef]

51. De Miguel, M.; Cabezas, J.A.; de María, N.; Sánchez-Gómez, D.; Guevara, M.Á.; Vélez, M.D.; Sáez-Laguna, E.; Díaz, L.-M.; Mancha, J.-A.; Barbero, M.-C.; et al. Genetic control of functional traits related to photosynthesis and water use efficiency in Pinus pinaster Ait. drought response: Integration of genome annotation, allele association and QTL detection for candidate gene identification. BMC Genom. 2014, 15, 1-19. [CrossRef]

52. Ukrainetz, N.K.; Ritland, K.; Mansfield, S.D. Identification of quantitative trait loci for wood quality and growth across eight full-sib coastal Douglas-fir families. Tree Genet. Gen. 2008, 4, 159-170. [CrossRef]

53. Lind, M.; Källman, T.; Chen, J.; Ma, X.F.; Bousquet, J.; Morgante, M.; Zaina, G.; Karlsson, B.; Elfstrand, M.; Lascoux, M.; et al. A Picea abies linkage map based on SNP markers identifies QTLs for four aspects of resistance to Heterobasidion parviporum infection. PLoS ONE 2014, 9, e101049. [CrossRef]

54. Zhao, Z.; Andersen, S.U.; Ljung, K.; Dolezal, K.; Miotk, A.; Schultheiss, S.J.; Lohmann, J.U. Hormonal control of the shoot stem-cell niche. Nature 2010, 465, 1089-1092. [CrossRef]

55. Cortizo, M.; Alvarez, J.M.; Rodríguez, A.; Fernández, B.; Ordás, R.J. Cloning and characterization of a type-A response regulator differentially expressed during adventitious shoot formation in Pinus pinea L. J. Plant. Physiol. 2010, 167, $1023-1026$. [CrossRef] [PubMed]

56. Drost, D.R.; Puranik, S.; Novaes, E.; Novaes, C.R.; Dervinis, C.; Gailing, O.; Kirst, M. Genetical genomics of Populus leaf shape variation. BMC Plant. Biol. 2015, 15, 1-10. [CrossRef] [PubMed]

57. Scalfi, M.; Troggio, M.; Piovani, P.; Leonardi, S.; Magnaschi, G.; Vendramin, G.; Menozzi, P. A RAPD, AFLP and SSR linkage map, and QTL analysis in European beech (Fagus sylvatica L.). Theor. Appl. Genet. 2004, 108, 433-441. [CrossRef] [PubMed]

58. Ishizuka, W.; Ono, K.; Hara, T.; Goto, S. Influence of low-and high-elevation plant genomes on the regulation of autumn cold acclimation in Abies sachalinensis. Front. Plant. Sci. 2015, 6, 890. [CrossRef] [PubMed]

59. Grattapaglia, D.; Bertolucci, F.L.; Penchel, R.; Sederoff, R.R. Genetic mapping of quantitative trait loci controlling growth and wood quality traits in Eucalyptus grandis using a maternal half-sib family and RAPD markers. Genetics 1996, 144, 1205-1214. [CrossRef] [PubMed]

60. Maxwell, K.; Johnson, G.N. Chlorophyll fluorescence-A practical guide. J. Exp. Bot. 2000, 51, 659-668. [CrossRef]

61. Robakowski, P. Susceptibility to low-temperature photoinhibition in three conifers differing in successional status. Tree Physiol. 2005, 25, 1151-1160. [CrossRef]

62. Chapin, F.S., III. Morphological and physiological mechanisms of temperature compensation in phosphate absorption along a latitudinal gradient. Ecology 1974, 55, 1180-1198. [CrossRef] 